\section{Lipopolysaccharide-Induced Nitric Oxide and Prolyl Oligopeptidase - Inhibitory Activities of Triterpenoids from Sanguisorba officinalis}

\author{
Hongyu Ma, Xizhe Li, Yuchen Zhang, Guangsong Chu, Zhong \\ Yuan
}

School of Traditional Chinese Materia Medica, Shenyang Pharmaceutical University, Shenyang, People's Republic of China

\section{Abstract \\ $\nabla$}

Lipopolysaccharide-induced nitric oxide and the protease prolyl oligopeptidase (EC 3.4.21.26) have been proposed as targets for the treatment of cognitive disturbances such as dementia. In this study, nine triterpenoids isolated from the roots of Sanguisorba officinalis, including arjunic acid (1), rosamultic acid (2), haptadienic acid (3), 1 $\beta$-hydroxyeuscaphic acid (4), euscaphic acid (5), tormentic acid (6), pomolic acid (7), ursolic acid (8), and oleanolic acid (9), were tested in vitro for their inhibitory activities on lipopolysaccharide-induced nitric oxide in N9 microglia cells and on prolyl oligopeptidase. Among them, 7 exhibited the strongest inhibitory activity on lipopolysaccharide-induced nitric oxide $\left(\mathrm{IC}_{50}\right.$, $21.9 \mu \mathrm{M}$ ), while $\mathbf{8}$ and $\mathbf{9}$ exhibited a significant prolyl oligopeptidase inhibitory activity ( $\mathrm{IC}_{50} 18.1$ and $24.0 \mu \mathrm{M}$, respectively). The results could provide a clue that these triterpenoids are responsible for the reported neuro-protective effect of $S$. officinalis.

Key words

Sanguisorba officinalis · Rosaceae · triterpenoids · lipopolysaccharide-induced nitric oxide · prolyl oligopeptidase

The dried roots of Sanguisorba officinalis L. (Rosaceae) are used in traditional Chinese medicine for the treatment of disorders such as bleeding, burns, ulcerative colitis, and chronic intestinal infections, due to their hemostatic, anti-infective, antibacterial, and anti-inflammatory activities [1-8]. Previous chemical investigations of $S$. officinalis revealed the existence of triterpenes, triterpenoids, saponins and polyphenols [3-6]. Moreover, S. officinalis and its active component (catechin) have been reported to possess potential neuroprotective effects and antioxidant activities [3-8]. Our interest in the constituents possibly responsible for these beneficial properties inspired us to undertake a further biological investigation of $S$. officinalis.

Nitric oxide (NO) released by N9 microglia (stimulated by lipopolysaccharide; LPS) is known as a neurotoxic factor and has a great influence on the cell viability of microglia. Microglia, the resident macrophage-like cells in the brain, have been proposed to play a pivotal role in the immune surveillance of the central nervous system [9]. Furthermore, lines of evidence showed that microglia-mediated neuroinflammation contributes to the pathology of both acute pathologies such as stroke or traumatic brain injury and chronic neurodegenerative diseases [10-12].

The protease prolyl oligopeptidase (POP; EC 3.4.21.26) has been proposed to play an important role in the neuropeptide metabolism and to be a target for the treatment of cognitive disturbances such as dementia [13-15]. It has been postulated that specific POP inhibitors could protect nerve cells, prevent memory loss, and enhance cognition [16-18]. Therefore, POP inhibitors have been developed as candidate drugs for the treatment of various clinical conditions of the brain [19]. Some natural POP inhibitors, especially triterpenoids from medical plants, have also been reported [1,20-22].

Identifying LPS-induced NO and POP inhibitors might lead to a better understanding of the potential neuroprotective benefits of S. officinalis. In our present work, dried roots of S. officinalis were extracted with $70 \%$ ethanol and the concentrated extract was partitioned with ethyl acetate (EtOAc) and water. From the EtOAc-soluble fraction, nine triterpenoids (1-9) were prepared and then tested in vitro for LPS-induced NO in N9 microglia cell and POP inhibitory activities.

The dried roots $(8 \mathrm{~kg})$ of $S$. officinalis were extracted with $70 \%$ ethanol and the concentrated extract was partitioned with EtOAc and water. In an investigation of the LPS-induced NO and POP inhibitory activities, the EtOAc-soluble fraction showed noticeable activities (NO inhibition rate of $100 \mu \mathrm{g} / \mathrm{mL}, 68.3 \pm 0.63 \%$; POP inhibition rate of $100 \mu \mathrm{g} / \mathrm{mL}, 93.40 \pm 0.52 \%$ ). Compounds $1-9$ were obtained from the EtOAc-soluble fraction after purification by polyamide, ODS C-18, Sephadex LH 20, and silica gel column chromatography. By comparison with published spectral data, the isolated triterpenoids were determined as arjunic acid (1), rosamultic acid (2), haptadienic acid (3), 1 $\beta$-hydroxyeuscaphic acid (4), euscaphic acid (5), tormentic acid (6), pomolic acid (7), ursolic acid (8), and oleanolic acid (9), respectively (๑ Fig. 1) [23-24]. HPLC analysis also demonstrated that the EtOAc-soluble fraction was triterpenoid-rich ( $\bullet$ Fig. 2 ).

Compounds 1-9 (purity > 95\% as indicated by HPLC analysis) and resveratrol (a natural polyphenol that potently inhibits the production of NO by LPS-activated microglia; purity $\geq 98.0 \%$ ) were evaluated for their inhibitory activities against LPS-induced NO [25]. Among them, compound 7 exhibited a moderate activity $\left(\mathrm{IC}_{50}, 21.9 \mu \mathrm{M}\right)$ comparable to the positive control resveratrol ( $\left.\mathrm{IC}_{50}, 15.1 \mu \mathrm{M}\right)$, while the activities of the other compounds were negligible. Meanwhile, compounds 1-9 and bacitracin [a bacteria peptide and natural POP inhibitor; potency (as bacitracin A): min. 40 units/mg] were measured for their POP inhibitory activities. Compared with the positive control bacitracin ( $\left.\mathrm{IC}_{50}, 14.9 \mu \mathrm{M}\right), 8$ and 9 exhibited a moderate activity ( $\mathrm{IC}_{50} 18.1$ and $24.0 \mu \mathrm{M}$, respectively) and showed no significant difference to the reported data [21]. Ursolic acid (8) and oleanolic acid (9) are isomers, only different at the $29-\mathrm{CH}_{3}$ linkage and their POP inhibitory activities were also similar. However, the hydroxyl substituted derivatives of ursolic acid, such as $1 \beta$-hydroxyeuscaphic acid (4), euscaphic acid (5), and pomolic acid (7) had lost these activities ( Table 1), which suggests that the hydroxyl groups substituted on ursolic acid or oleanolic acid are the obstacles of their POP inhibitory activities. It also suggests that the triterpenoid-rich fraction (the EtOAc-soluble fraction) is responsible for the reported neuroprotective effect of $S$. officinalis, and deserves to be further investigated.

\section{Materials and Methods \\ $\nabla$}

\section{General}

The NMR spectra were recorded on a Bruker ARX-600 (600 MHz) instrument with TMS as internal standard. The absorbance was obtained on microplate reader (Synergy HT, BioTek). 3-[4,5-dimethylthiazol-2-yl]-2,5-diphenyltetrazolium bromide (MTT) and LPS from Escherichia coli 026:B6 were purchased from Sigma 


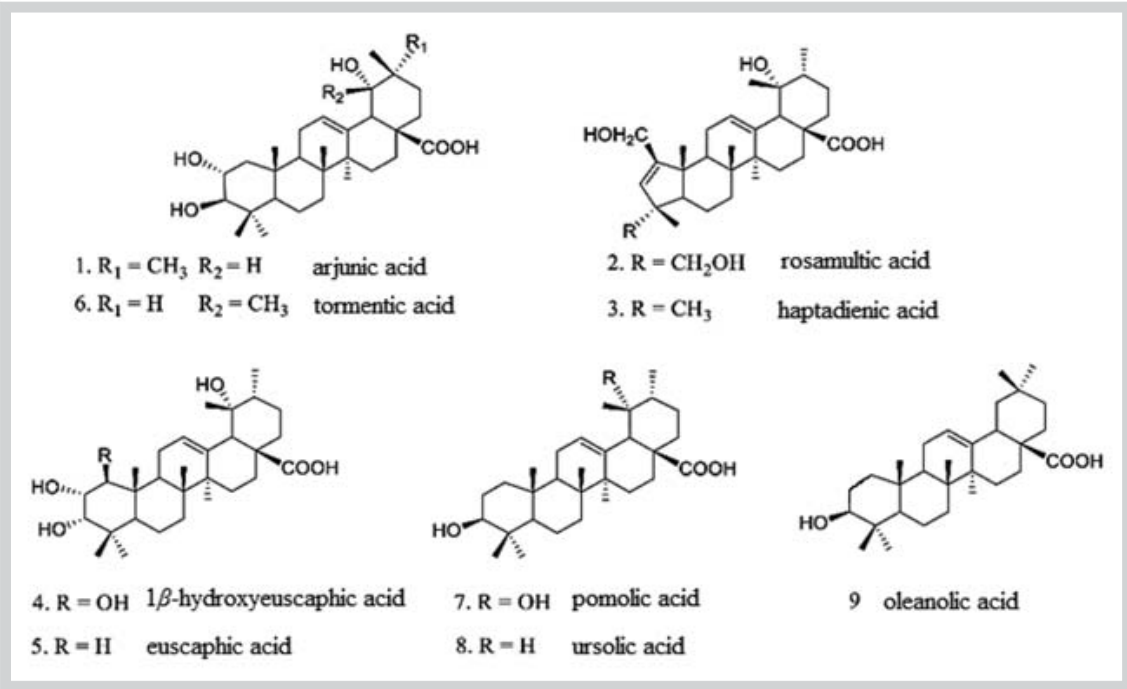

Fig. 1 Structures of compounds $\mathbf{1 - 9 .}$

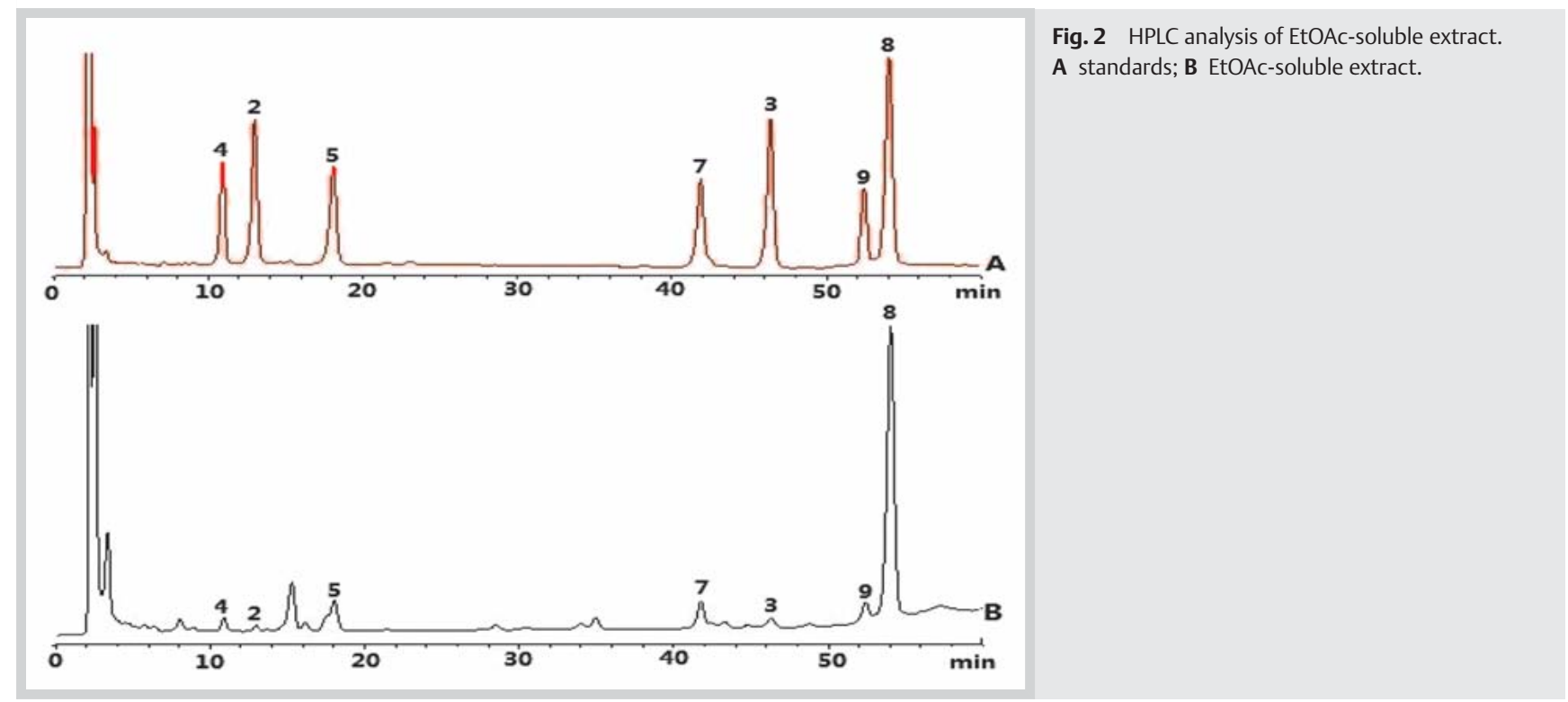

Chemical Co. Z-Gly-Pro-AMC was purchased from Bachem AG Chemical Co. HPLC analysis was performed using a Shimadzu HPLC system.

\section{Plant material}

S. officinalis roots were collected in November 2011 in Benxi, Liaoning Province, China and identified by Prof. Weichun Wu of the Shenyang Phamaceutical University, Shenyang, China. A voucher specimen (NO. 20111015) was deposited in the School of Traditional Chinese Materia Medica, Shenyang Pharmaceutical University.

\section{Extraction and isolation}

Dried and powdered plant material $(8 \mathrm{~kg}$ ) was refluxed with $70 \%$ ethanol for two hours $(10 \mathrm{~L} \times 3$ times) and the ethanol extract was concentrated under reduced pressure to give a residue $(2130 \mathrm{~g})$. The residue was suspended in water and partitioned with EtOAc and then exhaustively evaporated to yield an EtOAc extract (425 g) and water extract (542 g). The EtOAc-soluble extract was subjected to polyamide column chromatography and
Table 1 Anti-inflammatory activities of compounds $\mathbf{1 - 9}$ and controls.

\begin{tabular}{|c|c|c|}
\hline Compound & $\begin{array}{l}\text { POP inhibition } \\
I_{50}(\mu \mathrm{M})\end{array}$ & $\begin{array}{l}\text { NO inhibition } \\
\mathrm{IC}_{50}(\mu \mathrm{M})\end{array}$ \\
\hline Arjunic acid (1) & $>100$ & $>100$ \\
\hline Rosamultic acid (2) & $>100$ & $>100$ \\
\hline Haptadienic acid (3) & $93.2 \pm 1.3$ & $>100$ \\
\hline $1 \beta$-hydroxyeuscaphic acid (4) & $>100$ & $>100$ \\
\hline Euscaphic acid (5) & $>100$ & $>100$ \\
\hline Tormentic acid (6) & $>100$ & $>100$ \\
\hline Pomolic acid (7) & $>100$ & $21.9 \pm 0.3$ \\
\hline Ursolic acid (8) & $18.1 \pm 1.3$ & $>100$ \\
\hline Oleanolic acid (9) & $24.0 \pm 1.4$ & $>100$ \\
\hline bacitracin & $14.9 \pm 1.2$ & - \\
\hline resveratrol & - & $15.1 \pm 0.5$ \\
\hline
\end{tabular}

eluted with an EtOH- $\mathrm{H}_{2} \mathrm{O}$ gradient system. The 25\% ethanol eluted fraction ( $50.5 \mathrm{~g}$ ) was then subjected to column chromatography over silica gel combined with Sephadex LH-20 and ODS 
column chromatography and recrystallization to give compounds 1 (5 mg), 2 (9 mg), 3 (10 mg), 4 (15 mg), 5 (20 mg), 6 (5 mg), 7 (20 mg), 8 (30 mg), 9 (19 mg).

\section{HPLC analysis}

HPLC was carried out on a Kromasil $C_{18}$ column $(200 \mathrm{~mm} \times$ $4.6 \mathrm{~mm}$ i.d., $5 \mu \mathrm{m}$ ) under the following chromatographic conditions: sample injection volume, $20 \mu \mathrm{L}$; column temperature, $30^{\circ} \mathrm{C}$; flow rate, $0.8 \mathrm{~mL} / \mathrm{min}$; mobile phase, acetonitrile (A) and $1.25 \%$ aqueous phosphoric acid $(\mathrm{v} / \mathrm{v}, \mathrm{B})$. A gradient program was used according to the following profile: $0-16 \mathrm{~min}, 47-48 \% \mathrm{~A}$; $16-$ $63 \mathrm{~min}, 48-74 \% \mathrm{~A}$. The wavelength of UV detection was set at $206 \mathrm{~nm}$. Sample was dissolved in acetonitrile and filtered through an ultramembrane filter (pore size $0.45 \mu \mathrm{m}$ ) before being used. Compounds 2-5, 7-9 were dissolved in acetonitrile as mixture standards.

\section{Microglial cell culture}

The murine microglia cell line N9 was a kind gift from Dr. P. Ricciardi-Castagnoli (Universita Degli Studi di Milano-Bicocca, Milan, Italy). The cells were similar to primary microglia in producing NO and various cytokines after stimulation. N9 cells were cultured in IMDM supplemented with 5\% FBS, 2 mM glutamine, $100 \mathrm{U} / \mathrm{mL}$ penicillin, and $100 \mathrm{mg} / \mathrm{mL}$ streptomycin at $37^{\circ} \mathrm{C}$ in humidified $5 \% \mathrm{CO}_{2}[26]$.

\section{Measurement of cell viability}

Cell viability was evaluated by MTT reduction assay [27]. In brief, $\mathrm{N} 9$ cells at $1 \times 10^{5}$ cells/well were seeded into 96-well plates. After various treatments for $24 \mathrm{~h}$, the medium was removed and the cells were incubated with MTT $(0.25 \mathrm{mg} / \mathrm{mL})$ for $3 \mathrm{~h}$ at $37^{\circ} \mathrm{C}$. The formazan crystals in the cells were solubilized with DMSO. The level of MTT formazan was determined by measuring its absorbance at $490 \mathrm{~nm}$ using a microplate reader.

\section{Nitric oxide assay}

Accumulation of nitrite $\left(\mathrm{NO}_{2}^{-}\right)$, an indicator of NO synthase activity, in cell culture supernatant was measured by the Griess reaction [28]. N9 cells $\left(1 \times 10^{5}\right.$ cells/well) were seeded into 96-well plates and treated with each sample (dissolved in DMSO) for $2 \mathrm{~h}$ and then stimulated with $1 \mathrm{mg} / \mathrm{mL}$ LPS. After incubation for $24 \mathrm{~h}$, $50 \mu \mathrm{L}$ of culture supernatant was mixed with equal volume of Griess reagent (part I: $1 \%$ sulfanilamide; part II: $0.1 \%$ naphthylethylene diamide dihydrochloride and $2 \%$ phosphoric acid) at room temperature. Fifteen minutes later, the absorbance was determined at $540 \mathrm{~nm}$ using a microplate reader.

\section{Prolyl oligopeptidase assay}

The inhibitory activity against POP from porcine brain was measured by fluorescence spectrophotometer as described by Wallén et al. [29-30]. Z-Gly-Pro-AMC was used as the substrate. Formation of 7-amino-4-methylcoumarin (AMC) was determined fluorometrically and the excitation and emission wavelengths were 380 and $460 \mathrm{~nm}$, respectively.

\section{Data analysis}

Results were expressed as mean \pm S.E. M. of three independent experiments performed in triplicates. One-way ANOVA followed by Dunnett's t-test was used for statistical analysis (SPSS 20.0 software). The $\mathrm{IC}_{50}$ value was defined as the concentration of compound required to inhibit $50 \%$ of $\mathrm{NO}$ and POP activity, and determined by non-linear regression using GraphPad Prism 5.0 software.

\section{Acknowledgements}

$\nabla$

This work was supported by the National Natural Science Foundation of China (No. 30772718 ).

\section{Conflict of Interest}

$\nabla$

The authors declare no conflict of interest.

\section{References}

1 Amor EC, Villaseñor IM, Yasin A, Choudhary MI. Prolyl endopeptidase inhibitors from Syzygium samarangense (Blume) Merr. \& L. M. Perry. Z Naturforsch C 2004; 59: 86-92

2 Yu T, Lee YJ, Yang HM, Han S, Kim JH, Lee Y, Kim C, Han MH, Kim MY, Lee J, Cho JY. Inhibitory effect of Sanguisorba officinalis ethanol extract on NO and $\mathrm{PGE}_{2}$ production is mediated by suppression of NF- $\kappa \mathrm{B}$ and AP-1 activation signaling cascade. J Ethnopharmacol 2011; 138: 11-17

3 Da Rocha MD, Viegas FP, Campos HC, Nicastro PC, Fossaluzza PC, Fraga $C A$, Barreiro EJ, Viegas $C J r$. The role of natural products in the discovery of new drug candidates for the treatment of neurodegenerative disorders II: Alzheimer's disease. CNS Neurol Disord Drug Targets 2011; 10: 251-270

4 Katsube N, Sunaga K, Aishita H, Chuang DM, Ishitani R. ONO-1603, a potential antidementia drug, delays age-induced apoptosis and suppresses overexpression of glyceraldehyde-3-phosplhate dehydrogenase in cultured central nervous system neurons. J Pharmacol Exp Ther 1999; 288: 6-13

5 Liu X, Cui Y, Yu Q Yu B. Triterpenoids from Sanguisorba officinalis. Phytochemistry 2005; 66: 1671-1679

6 Zhang PY, Qin SH, Zhao HX, Wang FL, Guo HJ, Bai H. A new triterpenoid saponin from Sanguisorba officinalis. J Asian Nat Prod Res 2012; 14: 607-611

7 Hu J, Li H, Yang BS, Mao X, Shi XD. Nordammarane triterpenoids from Sanguisorba officinalis. Helv Chim Acta 2015; 2: 273-278

8 Liu X, Shi B, Yu B. Four new dimeric triterpene glucosides from Sanguisorba officinalis. Tetrahedron 2004; 60: 11647-11654

9 Lue LF, Kuо YM, Beach T, Walker DG. Microglia activation and antiinflammatory regulation in Alzheimer's disease. Mol Neurobiol 2010; 41: $115-128$

$10 \mathrm{Gu} J \mathrm{H}, \mathrm{Ge}$ JB, Li M, Wu F, Zhang W, Qin ZH. Inhibition of NF- $k$ B activation is associated with anti-inflammatory and anti-apoptotic effects of ginkgolide B in a mouse model of cerebral ischemia/reperfusion injury. Eur J Pharm Sci 2012; 47: 652-660

11 Hagberg H, Gressens P, Mallard C. Inflammation during fetal and neonatal life: Implications for neurologic and neuropsychiatric disease in children and adults. Ann Neurol 2012; 71: 444-457

12 Hao $Y$, Yang JY, Wu CF, Wu MF. Pseudoginsenoside-F11 decreases morphine-induced behavioral sensitization and extracellular glutamate levels in the medial prefrontal cortex in mice. Pharmacol Biochem Behav 2007; 86: 660-666

13 Polgár L. The prolyl oligopeptidase family. Cell Mol Life Sci 2002; 59: 349-362

14 Taylor WL, Dixon JE. Catabolism of neuropeptides by a brain proline endopeptidase. Biochem Biophys Res Commun 1980; 94: 9-15

15 Schneider JS, Giardiniere M, Morain P. Effects of the prolyl endopeptidase inhibitor S 17092 on cognitive deficits in chronic low dose MPTP-treated monkeys. Neuropsychopharmacology 2002; 26: 176182

16 Portevin B, Benoist A, Rémond G, Hervé Y, Vincent $M$, Lepagnol J, De Nanteuil $G$. New prolyl endopeptidase inhibitors: in vitro and in vivo activities of azabicyclo[2.2.2]octane, azabicyclo[2.2.1]heptane, and perhydroin-dole derivatives. J Med Chem 1996; 39: 2379-2391

17 Yoshimoto T, Kado K, Matsubara F, Koriyama N, Kaneto H, Tsura D. Specific inhibitors for prolyl endopeptidase and their anti-amnesic effect. J Pharmacobiodyn 1987; 10: 730-735

18 Park DH, Park SJ, Kim JM, Jung WY, Ryu JH. Subchronic administration of rosmarinic acid, a natural prolyl oligopeptidase inhibitor, enhances cognitive performances. Fitoterapia 2010; 81: 644-648 
19 Morain P, Robin JL, De Nanteuil G, Jochemsen R, Heidet V, Guez D. Pharmacodynamic and pharmacokinetic profile of S 17092, a new orally active prolyl endopeptidase inhibitor, in elderly healthy volunteers. A phase I study. Br J Clin Pharmacol 2000; 50: 350-359

20 Sultanova N, Makhmoor T, Yasin A, Abilov ZA, Omurkamzinova VB, Attaur-Rahman, Choudhary MI. Isotamarixen - a new antiodant and prolyl endopeptidase-inhibiting triterpenoid from Tamarix hipida. Planta Med 2004; 70: 65-67

21 Park YS, Jang HJ, Paik YS. Prolyl endopeptidase inhibitory activity of ursolic and oleanolic acids from Corni Fructus. Agric Chem Biotechnol 2005; 48: 207-212

22 Marques MR, Stüker C, Kichik N, Tarragó T, Giralt E, Morel AF, Dalcol II. Flavonoids with prolyl oligopeptidase inhibitory activity isolated from Scutellaria racemosa Pers. Fitoterapia 2010; 81: 552-556

23 Wang H, Yuan Z. Triterpenes of Sanguisorba officinalis L. Chin J Med Chem 2009; 19: 52-62

24 Turkmen Z, Klymchenko AS, Oncul S, Duportail G, Topcu G, Demchenko $A P$. A triterpene oleanolic acid conjugate with 3-hydroxyflavone derivative as a new membrane probe with two-color ratiometric response. J Biochem Biophys Methods 2005; 64: 1-18

25 Meng XL, Yang JY, Chen GL, Wang LH, Zhang LJ, Wang S, Li J, Wu CF. Effects of resveratrol and its derivatives on lipopolysaccharide-induced microglial activation and their structure-activity relationships. Chem Biol Interact 2008; 17: 451-459

26 Iribarren P, Chen KQ Hu JY, Zhang X, Gong WH, Wang JM. IL-4 inhibits the expression of mouse formyl peptide receptor 2, a receptor for amyloid beta1-42, in TNF- $\alpha$-activated microglia. J Immunol 2005; 175 : 6100-6106

27 Lee HJ, Maeng K, Dang HT, Kang GJ, Ryou C, Jung JH, Kang HK, Prchal JT, Yoo ES, Yoon D. Anti-inflammatory effect of methyl dehydrojasmonate (J2) is mediated by the NF-kB pathway. J Mol Med (Berl) 2011; 89: 8390

28 Chen $X$, Choi IY, Chang TS, Noh YH, Shin CY, Wu CF, Ko KH, Kim WK. Pretreatment with interferon-gprotects microglia from oxidative stress via up-regulation of Mn-SOD. Free Radic Biol Med 2009; 46: 1204-1210

29 Wallén EA, Christiaans JA, Saarinen TJ, Jarho EM, Forsberg MM, Venäläinen JI, Männistö PT, Gynther J. Conformationally rigid N-acyl-5alkyl-L-prolyl-pyrrolidines as prolyl oligopeptidase inhibitors. Bioorg Med Chem 2003; 11: 3611-3619

30 Wallén EA, Christiaans JA, Forsberg MM, Venäläinen JI, Männistö PT, Gynther J. Dicarboxylic acid bis(L-prolyl-pyrroldine) amides as prolyl oligopeptidase inhibitors. J Med Chem 2002; 45: 4581-4584

received September 22, 2015

revised March 2, 2016

accepted May 13, 2016

\section{Bibliography}

DOI http://dx.doi.org/10.1055/s-0042-108808

Planta Med Int Open 2016; 3: e39-e42

(c) Georg Thieme Verlag KG Stuttgart · New York ·

ISSN 2509-6656

\section{Correspondence}

\section{Zhong Yuan}

Department of Analysis of Traditional Chinese Medicine School of Traditional Chinese Materia Medica

Shenyang Pharmaceutical University

103 Wenhua Road

Shenyang 110016

People's Republic of China

Phone: + 8602423986469

Fax: + 862424824352

yuanzhong@syphu.edu.cn 